Volume 8, No.1.1, 2019

International Journal of Advanced Trends in Computer Science and Engineering

Available Online at http://www.warse.org/IJATCSE/static/pdf/file/ijatcse2781.12019.pdf

https://doi.org/10.30534/ijatcse/2019/2781.12019

\title{
Facebook Blog Innovation Experience, Course and Hosteller
}

\author{
Pankaj Deshwal $^{\# 1}$, Rishikesh Ranjan ${ }^{\# 2}$ \\ ${ }^{\#}$ Netaji Subhas Institute of Technology, Delhi, India \\ 1 pankajdeshwal@gmail.com \\ 2rishikeshranjan1996@gmail.com
}

\begin{abstract}
The success of innovations at Facebook has led it to become the reason why its popularity is unparalleled, and hence the reception of the innovations must be researched upon thoroughly. The objective of this research is to find out how groups based on different demographic categories, (course and residence) differ for the different factors obtained for Facebook blog service innovation as perceived by students that are studying in a higher technical institute of India. In order to fulfill this objective one-way ANOVA analysis is being performed on the reception of these innovations in the minds of technically advanced user segment of engineering students within the demographic distinctions of course and residence. Course and particularly residence plays a vital role in determining the choice of blogs and amount of time devoted at Facebook. The scale utilized for preparation of the questionnaire is BLOG-S-INNO scale. The results of the analysis may be utilized by concerned organizations for how to promote their products and services online on Facebook and may be useful for other social networking sites that are based, college-going users. The following study involves quantitative analysis done through a survey through the interactive mode of data collection of 172 users from a leading and renowned technical institute of New Delhi. The analysis was done through SPSS software to get an idea of the perception of an engineering student regarding innovation in social media service provider, Facebook. The study finds out the difference between the perceptions of respondents based upon demographic categories of course and residence in relation to Facebook in a higher technical institution. It puts the various domains on a 5-point scale, like the content, user interface, information sharing, diversity, privacy, and accessibility. The results may help the organization to strategize its steps ahead for better experience and satisfaction to students and thus further helping Facebook or other similar sites to increase service among the young students within these specific demographics.
\end{abstract}

Key words : Perception, Blogging service, ANOVA, Course, Blog Service Innovation, Facebook, Residence.

\section{INTRODUCTION}

Blogging being one of the major forms of expressing oneself provides an interactive, collaborative information-sharing environment. Therefore, it directly affects social media giants like Facebook and Twitter [1]. The way people are able to share images, videos, links and multimedia objects, makes the services by these giants a blogging arena. The following analysis includes a variety of fields like service delivery, service performance, and satisfaction of students diverse in course and residence, obtaining higher technical studies, about blogging innovations, experience on Facebook. The customer's viewpoints need to be looked after for improving its functionality and service quality. The dimensions that need to be further revamped and improved upon have been identified and enlisted. The expectations of the users also shape new features for a diverse platform such as Facebook, which is evident from the fact that it has recently included features like Facebook live, instant articles, and music stories. Such features have made this kind of blogging more sustaining and encompassing a large quantum of demands of the users. So after all such features, Facebook may be described as a platform where one can make friends, message through messenger, chat, share public as well as confidential information, along with adjusting the visibility of the posts one shares, make groups, follow others, make public pages, thus enabling various firms do a large part of their marketing through such platforms. The follower can get updated information in-group and on liked pages on their news feeds. One of the most creative features on Facebook is that one can even express his/her emotions and state of being by using emoticons and GIFs among all other ways. Facebook even offers a way of notifying the related people of the recent updates.

A firm established with the capacity and dedication towards expectations of its customers, could both create new customers and confirmation to its existing customers [2]. This research adheres to a customer-oriented approach for a service innovation project and difference in perception due to diversities in course and residence. As the service innovation creates values with collaborative user relationships, the job of the service provider is to find how to go through innovation as per the user experience. New services need to be developed to fulfill the requirements of users and boost the reach of the platform and similar platforms within selective user bases. Evidently, the users have even transformed the way of communication from calls to instant messaging and back to audio and video chats on Facebook. Continuous development and innovation should be the motto of every blog service platform so as to continue being effective, consequently, service innovation is thus needed for making social media platforms a big hit.

The usefulness of the following analysis is even demonstrated by various quantitative and qualitative analytical ways. Established blogging service providers must be able to 
clearly define their boundaries to enhance the worth of their service and new services catering user bases in colleges should understand and analyze these innovations for better confirmation of customers. The strategies for service innovation usually do not fulfill their purpose due to the risks associated with service innovation, service performance, and user satisfaction. This sort of quantitative analysis of the perceptions about Facebook in the minds of a student of different courses and residence options will enable and empower websites, blogging sites and in general any company catering innovations in their products and services in the user segment of college going students to improvise accordingly and increase consumer confirmation. Facebook blog service innovation perception has already been validated in the context of the students studying in higher technical institutions of India. The objectives of this research are how different groups within different demographic categories keep a different perspective about the factors obtained previously. In the methodology section of this paper, 12 null hypotheses are developed. This can be used for selective marketing strategy for companies and promote themselves at blog service provider platforms to the students of these different groups. The research limitations and options for future research in related domains are also given in the end.

\section{LITERATURE REVIEW}

The popularity of practicing blogging on social media and networking websites has witnessed an unprecedented rise in the past few years [3]. Service providers such as Facebook are able to provide user based updates, explanations, and clarifications about events and other websites, promoting links to other websites [4]. Blogging functions at such sites have made it possible to frequently restructure journals and article online with timed and scheduled entries in a manner different from many other [5]. Many researchers [6] have studied the reason why users love to share their blogs and read other blogs on the website. Blog service users often have many motives that are a combination of interest, ability to practice freedom of expression, urge to develop a social image and socializing skill sets, understand the concepts of various friends and acquaintances about topics that matter to them, and reply to other user's post, for reading other blogs or writing their own blogs. Blog service providers provide opportunities to individual or groups to be able to share their thoughts, life events and personality with other users online, thus creating virtually an identity of its users [7].

The web of interconnections between the users of the blog service provider allows a multitude of ways in which the users can communicate with each other, typically through personal messages and group chats but more recently through audio and video calls, and Facebook lives [8]. Since a very long time, one of the methods of attracting users to their websites has been adding an additional feature of blogging or another method of expression for numerous websites [9]. The advancements in blogging technology and popularity create a major demand for blogging functions to be a part of any websites [10]. 12 million people that make more than $8 \%$ of website users use blogging services and over $39 \%$ of the website users estimated to be 57 million people read those [11]. To get an estimate it was reported by Blog Pulse in 2011 that almost 150 million blog updates are posted on platforms in that year that allow users to blog, which is more than 27,000 new blogs per day.

ANOVA is a quantitative method that utilizes various statistical models to analyze the variances between two or more groups and helps in predicting where a significant difference is present in the responses of the two groups on a statement [12]. This analysis of variance or ANOVA technique was created by Ronald Fisher.

BLOGS-INNO instrument was obtained using both quantitative and qualitative methodologies of research. A variety of responses for analyzing blog service innovation was gathered by executing an instrument to find the knowledge of blog service innovation in blog users who stand as the participants.

The null hypotheses that are formulated for different factors for various groups within different demographic categories get rejected if the p-values for the corresponding hypothesis shows some notable variations in their means i.e. have values of $p$ less than 0.05 [13]. The six dimensions or factors that were identified [14-18] after validation of BLOG-S-INNO scale amongst the respondents i.e. students studying in the higher technical institute are as follows:
(a) User-interface
(b) Variability
(c) Privacy
(d) Content Catering
(e) Professionalism
(f) Socialism

\section{METHODOLOGY}

The questionnaire consisted of a total of 27 statements within 6 different categories of user-interface, variability, privacy, content catering, professionalism, socialism and respondents filled the questionnaires according to a 5-point Likert scale denoting 5 for being in strong agreement, 4 for having moderate agreement, 3 for neither agreement nor disagreement, 2 for being in moderate disagreement and 1 for having strong disagreement to the respective statement. A section for demographic details and another for extent, frequency, and duration of use were also added to the questionnaire. For this survey, the researchers chose a premium technical institute providing both undergraduate and postgraduate courses in India. The required data was collected through the personal mode of data collection and this process took the duration of four months from July 2016 to October 2016. The respondents of the survey were demographically diversified, differentiated based on their course of study, year in which they are currently studying, whether the respondent is a hosteller or a day boarder, proximity of the institute from the residence of the student if he is a non-hosteller, and age. 172 responses were deemed utilizable after filtering out nine survey forms that were found to be either incomplete or randomly filled. This research is a continued in-depth analysis 
of differences between the factors according to various courses and residence options.

ANOVA analysis was carried out on the factors with respect to different groups within the course and residence demographics to obtain an in-depth analysis of how the means differ within different groups. The conclusions were then drawn and future research work that could be conducted in related fields and importance of the conducted research was written down.

The following six factors and 2 demographic categories were utilized for formation of the research hypotheses - User Interface, Variability, Privacy, Socialism, Content Catering, Professionalism, and Course and Residence. Twelve research hypotheses were formulated, all being related to analysis based upon items formed through a combination of different factors and categories. The hypotheses formulated are null hypotheses and are given below:

A) For the examination if the output of the variations in different courses of the respondents while pursuing higher education has a considerable difference in their perception of the blogging website's user experience dimensions, the following hypotheses are selected:

$\mathrm{HO}_{1}$ : Differences in course will affect how users feel about user-interface of Facebook during their Facebook browsing experience.

$\mathrm{HO}_{2}$ : Differences in course will affect how users feel about variations offered at Facebook during their Facebook browsing experience.

$\mathrm{H}_{3}$ : Differences in course will affect how users feel about their privacy at Facebook during their Facebook browsing experience.

$\mathrm{HO}_{4}$ : Differences in course will affect how users feel about content that is catered at Facebook during their Facebook browsing experience.

$\mathrm{H}_{5}$ : Differences in course will affect how users feel about professionalism witnessed at Facebook during their Facebook browsing experience.

$\mathrm{H}_{6}$ : Differences in course will affect how users feel about the social advancements they gain during their Facebook browsing experience.

B) For the examination if the output of the variations in residence (whether the user is a hosteller or a day boarder) of the respondents that they choose while pursuing higher education has a considerable difference in their perception of the blogging website's user experience dimensions, the following six hypotheses are selected:

$\mathrm{HO}_{7}$ : Differences in residence will affect how users feel about user-interface of Facebook during their Facebook browsing experience.

$\mathrm{H}_{8}$ : Differences in residence will affect how users feel about variations offered at Facebook during their Facebook browsing experience.
$\mathrm{H}_{9}$ : Differences in residence will affect how users feel about their privacy at Facebook during their Facebook browsing experience.

$\mathrm{H}_{10}$ : Differences in residence will affect how users feel about content that is catered at Facebook during their Facebook browsing experience.

$\mathrm{HO}_{11}$ : Differences in residence will affect how users feel about professionalism witnessed at Facebook during their Facebook browsing experience.

$\mathrm{H}_{12}$ : Differences in residence will affect how users feel about the social advancements they gain during their Facebook browsing experience.

\section{ANALYSIS AND RESULTS}

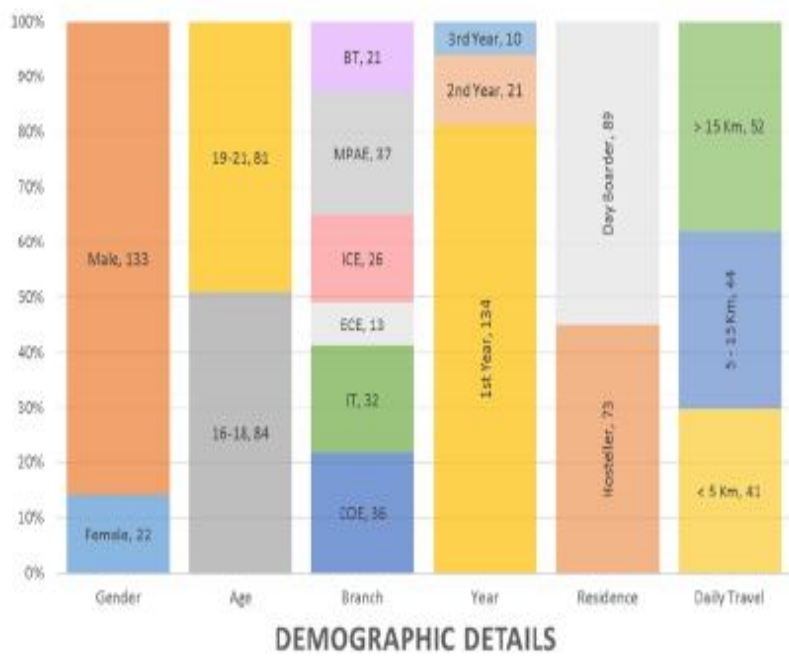

Figure 1: Demographic Details

\section{Descriptive analysis}

Of the total 172 students, surveyed nine respondent's questionnaire were determined to not being utilizable because of the data being incomplete for major portions of the survey questionnaire. With reference to the graph provided above, we are able to acknowledge our limitations, as the gender diversity with only $14 \%$ of the respondents being female was not adequate. Also, about $81 \%$ of the respondents were firstyear students, $13 \%$ were second-year students, and remaining $6 \%$ were third-year respondents. The students were further almost equally divided into all branches with only 1 stream having lesser number of participants. Due to restrictions in the domain, surveyed only three age groups within about 4 years of difference were included. The demographic analysis also assured that the respondents were from all financial backgrounds. About $44 \%$ of the respondents surveyed were hostellers. The $56 \%$ day scholars were equally divided into the 3 -proximity radius from college zones of $<5 \mathrm{~km}, 5-15 \mathrm{~km}$, and $>15 \mathrm{~km}$ zones. The data for hostellers and day scholars and courses distribution was selected as demographic categories for one-way ANOVA analysis (figure 1). 


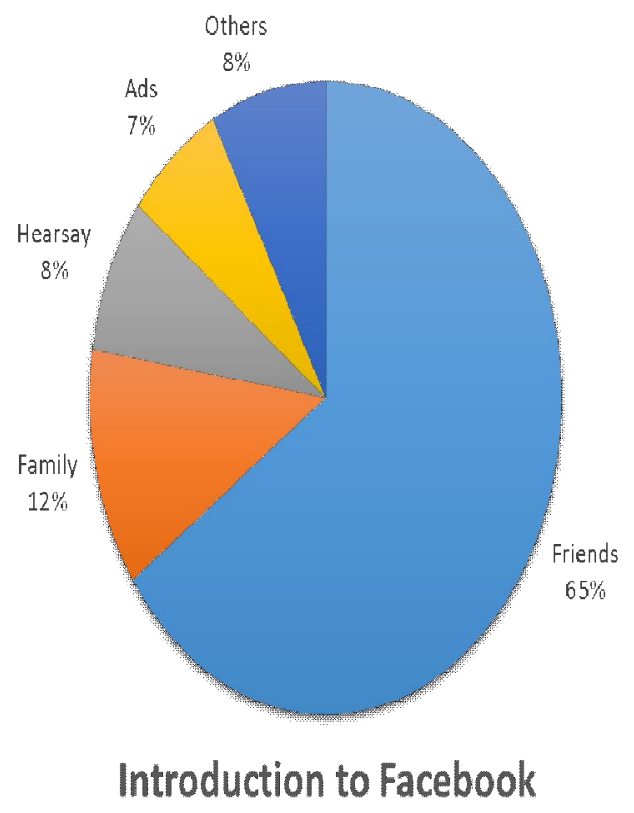

Figure 2: Introduction to Facebook

Through the survey, we were also able to determine that a majority of the respondents joined Facebook through friends (table 1). The advertisements about Facebook have also not been able to generate many new users as only $8 \%$ confirmed them a source of them being introduced to Facebook (figure 2).

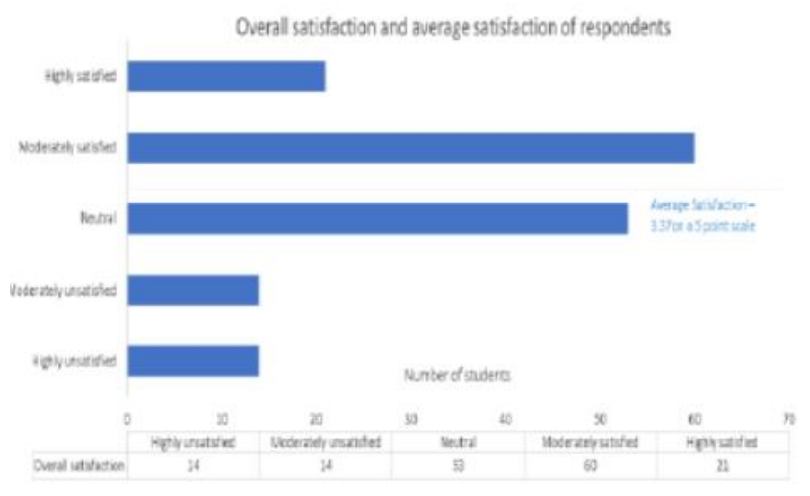

Figure 3: Overall and Average Satisfaction

The respondents also gave their feedback about the satisfaction of their use of Facebook and majority of the respondents were either happy or neutral about their experience (figure 3).

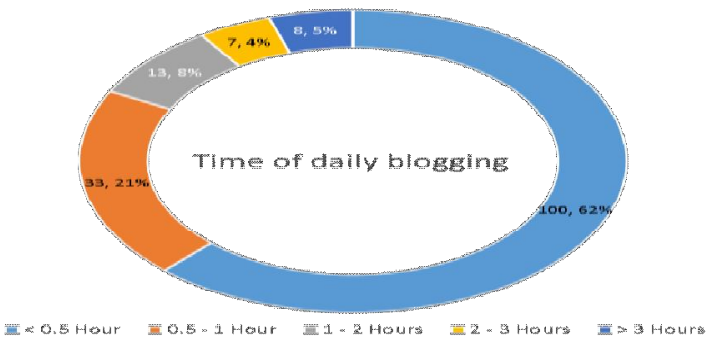

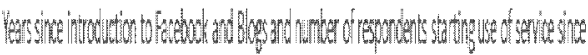

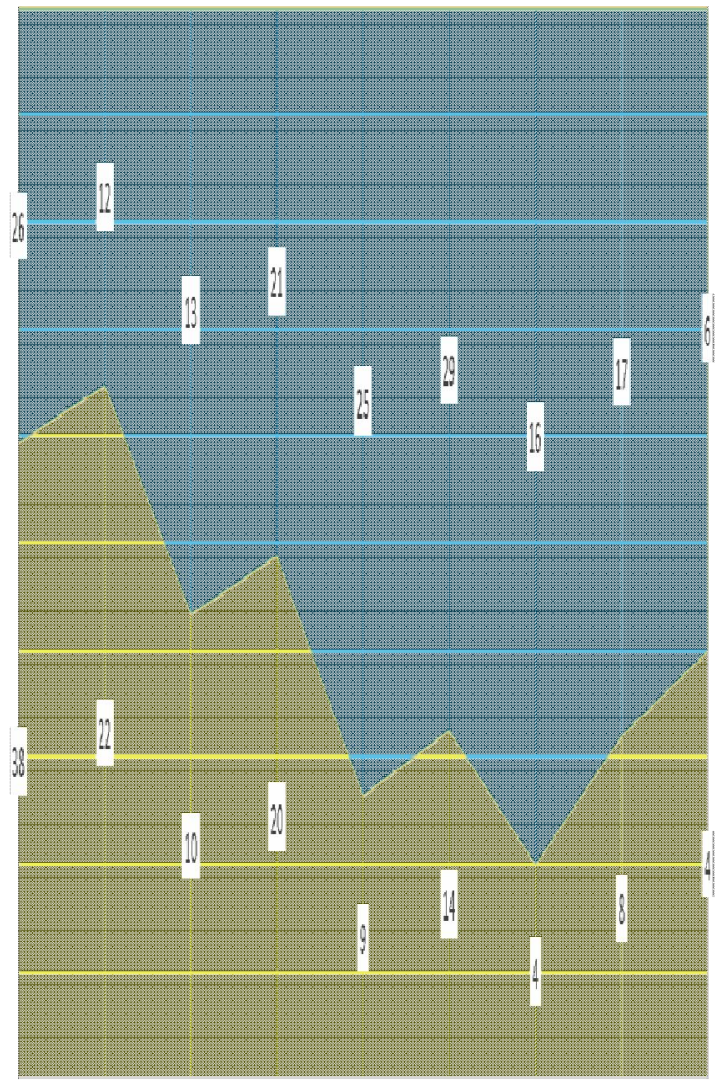

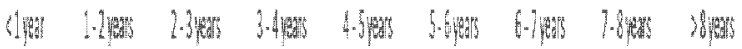

Figure 4: Use of Facebook Services

While the total number of respondents that use blogging service is still lesser than those who use Facebook, recently the number of blog and Facebook service users has increased (table 2). It is also understood that Facebook has reached a level of saturation and almost every individual responding to the survey has their accounts created before the start of college (figure 4).

It's also noted that about $62 \%$ users use Facebook for less than half hour a day and only $5 \%$ of students spend more than 3 hours a day on Facebook. Still, such large amounts of time for an undergraduate or postgraduate student consumed on socializing daily is problematic and needs to be looked at (figure 5).

Table 1: Anova results-course and facebook blog innovation experience dimensions

\begin{tabular}{|c|c|c|c|c|c|c|c|}
\hline Hypothesis & \multirow{2}{*}{ Factor } & $\begin{array}{c}\text { Sum of } \\
\text { Squares }\end{array}$ & df & $\begin{array}{c}\text { Mean } \\
\text { Square }\end{array}$ & F & Sig. \\
\cline { 4 - 7 } $\mathrm{H}_{1}$ & \multirow{2}{*}{$\mathrm{F} 1$} & Between Groups & .098 & 1 & .098 & .097 & .756 \\
\cline { 4 - 8 } & & Within Groups & 164.644 & 163 & 1.010 & & \\
\cline { 4 - 7 } & & Total & 164.742 & 164 & & & \\
\hline $\mathrm{H}_{2}$ & F 2 & Between Groups & .513 & 1 & .513 & .508 & .477 \\
\hline
\end{tabular}




\begin{tabular}{|c|c|c|c|c|c|c|c|}
\hline & & Within Groups & 164.442 & 163 & 1.009 & & \\
\hline & & Total & 164.955 & 164 & & & \\
\hline \multirow{3}{*}{$\mathrm{HO}_{3}$} & \multirow{3}{*}{ F 3} & Between Groups & .214 & 1 & 214 & 212 & .646 \\
\hline & & Within Groups & 164.240 & 163 & 1.008 & & \\
\hline & & Total & 164.453 & 164 & & & \\
\hline \multirow{3}{*}{$\mathrm{H}_{4}$} & \multirow{3}{*}{ F 4} & Between Groups & .092 & 1 & .092 & .093 & .761 \\
\hline & & Within Groups & 161.095 & 163 & .988 & & \\
\hline & & Total & 161.186 & 164 & & & \\
\hline \multirow{3}{*}{$\mathrm{H}_{5}$} & \multirow{3}{*}{ F 5} & Between Groups & 5.378 & 1 & 5.378 & 5.510 & .020 \\
\hline & & Within Groups & 159.098 & 163 & .976 & & \\
\hline & & Total & 164.476 & 164 & & & 1 \\
\hline \multirow{3}{*}{$\mathrm{H}_{6}$} & \multirow{3}{*}{ F 6} & Between Groups & .092 & 1 & .092 & .091 & .763 \\
\hline & & Within Groups & 164.518 & 163 & 1.009 & & \\
\hline & & Total & 164.610 & 164 & & & \\
\hline
\end{tabular}

Table 2. Anova results in inhosteller and facebook blog innovation experience dimensions

\begin{tabular}{|c|c|c|c|c|c|c|c|}
\hline Hypothesis & & Factor & $\begin{array}{l}\text { Sum of } \\
\text { Squares }\end{array}$ & df & $\begin{array}{l}\text { Mean } \\
\text { Square }\end{array}$ & $\mathbf{F}$ & Sig. \\
\hline \multirow{3}{*}{$\mathrm{HO}_{7}$} & \multirow{3}{*}{ F 1} & Between Groups & 6.271 & 2 & 3.135 & \multicolumn{2}{|c|}{3.205 .043} \\
\hline & & Within Groups & 158.471 & 162 & .978 & & \\
\hline & & Total & 164.742 & 164 & & & \\
\hline \multirow{3}{*}{$\mathrm{H}_{8}$} & \multirow{3}{*}{ F 2} & Between Groups & .770 & 2 & .385 & .380 & .685 \\
\hline & & Within Groups & 164.185 & 162 & 1.013 & & \\
\hline & & Total & 164.955 & 164 & & & \\
\hline \multirow{3}{*}{$\mathrm{HO}_{9}$} & \multirow{3}{*}{ F 3} & Between Groups & 1.992 & 2 & .996 & \begin{tabular}{|c|}
.993 \\
\end{tabular} & .373 \\
\hline & & Within Groups & 162.462 & 162 & 1.003 & & \\
\hline & & Total & 164.453 & 164 & & & \\
\hline \multirow{3}{*}{$\mathrm{HO}_{10}$} & \multirow{3}{*}{ F 4} & Between Groups & .105 & 2 & .052 & .053 & .949 \\
\hline & & Within Groups & 161.081 & 162 & .994 & & \\
\hline & & Total & 161.186 & 164 & & & \\
\hline \multirow{3}{*}{$\mathrm{H} 0_{11}$} & \multirow{3}{*}{ F 5} & Between Groups & 1.926 & 2 & .963 & .960 & .385 \\
\hline & & Within Groups & 162.550 & 162 & 1.003 & & \\
\hline & & Total & 164.476 & 164 & & & \\
\hline \multirow{3}{*}{$\mathrm{H}_{12}$} & \multirow{3}{*}{ F 6} & Between Groups & 4.146 & 2 & 2.073 & 2.093 & .127 \\
\hline & & Within Groups & 160.464 & 162 & .991 & & \\
\hline & & Total & 164.610 & 164 & & & \\
\hline
\end{tabular}

\section{CONCLUSIONS AND MANAGERIAL IMPLICATIONS}

This paper portrays statistically that a difference among the course category and residence category is present in one element or factor of Facebook blog service innovation experience each viz. $\mathrm{H}_{5}$ and $\mathrm{H}_{7}$ in respondents from a higher technical institute of India. Apart from these two hypotheses, all other null hypotheses were found to be true, hence suggesting no major gap in between the perceptions of the groups within the categories of course and residence.

$\mathrm{H}_{5}$ : Differences in course will affect how users feel about professionalism witnessed at Facebook during their Facebook browsing experience.

$\mathrm{H}_{7}$ : Differences in residence will affect how users feel about user-interface of Facebook during their Facebook browsing experience.

The hypothesis $\mathrm{H}_{5}$ has shown that students of different courses perceive professionalism offered by content on Facebook differently, and hence companies targeting the selective audience of college going institutes should strategize accordingly.
The hypothesis $\mathrm{H}_{7}$ shows that there is a difference in between what hostellers and non-hostellers think about the user interface of the social networking site, which can be quite helpful to understand the difference and apply it to a product or service designed for college going students. Marketing strategy for targeting the two groups by a company with interest in this demographic section must be different for each group.

\section{CONCLUSIONS AND FUTURE RESEARCH}

The statistical data for analysis of variable to be used was limited and would have given results that are more precise if the number of respondents was greater. This research can specifically be helpful to other blog service providers and companies that utilize blogging as a method to promote and market their products and services. Future studies can also utilize this paper as a basis for expansion and generalization of blog service innovation through ANOVA tests on other demographics and outside the context of respondents being only from the higher technical institution. The survey sample size can also be increased for better means and results that are more precise.

\section{REFERENCES}

[1]S. Matei, "Analyzing Social Media Networks with NodeXL: Insights from a Connected World by Derek Hansen, Ben Shneiderman, and Marc A. Smith", International Journal of Human-Computer Interaction, vol. 27, no. 4, pp. 405-408, 2011.

https://doi.org/10.1080/10447318.2011.544971

[2] P. Kotler, "The Major Tasks of Marketing Management", Journal of Marketing, vol. 37, no. 4, p. 42, 1973. https://doi.org/10.1177/002224297303700407

[3] R. Kwai Fun IP and C. Wagner, "Weblogging: A study of social computing and its impact on organization", Decision Support Systems, vol. 45, no. 2, pp. 242-250, 2008.

https://doi.org/10.1016/j.dss.2007.02.004

[4] T. Johnson and B. Kaye, "Wag the Blog: How Reliance on Traditional Media and the Internet Influence Credibility Perceptions of Weblogs Among Blog Users", Journalism \& Mass Communication Quarterly, vol. 81, no. 3, pp. 622642, 2004. https://doi.org/10.1177/107769900408100310

[5] Y. Li and C. Chen, "A synthetical approach for blog recommendation: Combining trust, social relation, and semantic analysi", Expert Systems with Applications, vol. 36, no. 3, pp. 6536-6547, 2009.

https://doi.org/10.1016/j.eswa.2008.07.077

[6]A. Miura and K. Yamashita, "Psychological and Social Influences on Blog Writing: An Online Survey of Blog Authors in Japan", Journal of Computer-Mediated Communication, vol. 12, no. 4, pp. 1452-1471, 2007. https://doi.org/10.1111/j.1083-6101.2007.00381.x

[7]H. Ko, C. Yin and F. Kuo, "Exploring individual communication power in the blogosphere", Internet Research, vol. 18, no. 5, pp. 541-561, 2008. https://doi.org/10.1108/10662240810912774

[8] H. Du and C. Wagner, "Weblog success: Exploring the role of technology", International Journal of HumanComputer Studies, vol. 64, no. 9, pp. 789-798, 2006. https://doi.org/10.1016/j.ijhcs.2006.04.002

[9]C. Shen and J. Chiou, "The effect of community identification on attitude and intention toward a blogging community", Internet Research, vol. 19, no. 4, pp. 393407, 2009.

https://doi.org/10.1108/10662240910981362 
Pankaj Deshwal et al., International Journal of Advanced Trends in Computer Science and Engineering, 8(1.1), 2019,145 - 150

[10]R. Kumar, J. Novak, P. Raghavan, and A. Tomkins, "Structure and evolution of blog space", Communications of the ACM, vol. 47, no. 12, p. 35, 2004. https://doi.org/10.1145/1035134.1035162

[11] R. Netemeyer, S. Burton and D. Lichtenstein, "Trait Aspects of Vanity: Measurement and Relevance to Consumer Behavior", Journal of Consumer Research, vol. 21, no. 4, p. 612, 1995 . https://doi.org/10.1086/209422

[12]D. C. Hoaglin, and R. E. Welsch, "The Hat Matrix in Regression and ANOVA," The American Statistician, 32, pp. $17-22,1978$.

[13] A. Shekarchizadeh, A. Rasli and H. HonTat, "SERVQUAL in Malaysian universities: perspectives of international students", Business Process Management Journal, vol. 17, no. 1, pp. 67-81, 2011. https://doi.org/10.1108/14637151111105580

[14]P. Deshwal, S. Hans, R. Ranjan and R. Rawat" Facebook blog innovation experience 2017 4th International Conference on "Computing for Sustainable Global Development", 01st-03rd March 2017 Bharati Vidyapeeth's Institute of Computer Applications and Management (BVICAM), New Delhi (INDIA), pp. 2548-2552.
[15]P. Deshwal, "Customer experience quality and demographic variables (age, gender, education level, and family income) in retail stores", International Journal of Retail \& Distribution Management, vol. 44, no. 9, pp. 940955, Sep. 2016. https://doi.org/10.1108/IJRDM-03-2016-0031

[16] P. Deshwal, V. Ranjan, and G. Mittal, "College clinic service quality and patient satisfaction", International Journal of Health Care Quality Assurance, vol. 27, no. 6, pp. 519-530, Jul. 2014. https://doi.org/10.1108/IJHCQA-06-2013-0070

[17] P. Deshwal and P. Bhuyan, "Cancer patient service experience and satisfaction", International Journal of Healthcare Management, pp. 1-8, Nov. 2016.

[18] P. Deshwal and A. Krishna. Customer service experience and satisfaction in retail stores. In 2016 3rd International Conference on Computing for Sustainable Global Development (INDIACom), IEEE, 2016. 